\title{
Effect of Al content on the critical resolved shear stress for twin nucleation and growth in Mg alloys
}

\author{
Jingya Wang ${ }^{\mathrm{a}, \mathrm{b}}$, Jon M. Molina-Aldareguía ${ }^{\mathrm{a}}$, Javier LLorca ${ }^{\mathrm{a}, \mathrm{b},{ }^{*}}$ \\ aIMDEA Materials Institute, C/Eric Kandel 2, 28906, Getafe, Madrid, Spain \\ ${ }^{b}$ Department of Materials Science, Polytechnic University of Madrid/Universidad \\ Politécnica de Madrid, E.T.S. de Ingenieros de Caminos, 28040 Madrid, Spain
}

\begin{abstract}
The effect of $\mathrm{Al}$ atoms in solid solution on the critical resolved shear stress for twin nucleation and growth was analyzed by means of the combination of diffusion couples with compression tests in micropillars oriented for twinning. The critical resolved shear stress for twin nucleation was higher than that for twin growth and both increased by the same amount with the Al content. Nevertheless, the increase was small $(\approx 10 \mathrm{MPa})$ for 4 at.\%Al but large (up to $60-70 \mathrm{MPa}$ ) for 9 at.\%Al. These results were in agreement with Labusch-models based on first principles calculations in the dilute regime $(<5$ at.\%Al) [51]. Comparison with recent data in the literature showed that $\mathrm{Al}$ atoms are more effective in increasing the critical resolved shear stresses for twin nucleation and growth than for basal slip [21]. Finally, compression tests in micropillars oriented along [0001] showed the critical shear stress for pyramidal slip increased rapidly with the Al content from $98 \mathrm{MPa}$ in pure $\mathrm{Mg}$ to $250 \mathrm{MPa}$ in $\mathrm{Mg}-9$ at.\%Al. Thus, the addition of $\mathrm{Al}$ increased the plastic anisotropy of $\mathrm{Mg}$ alloys.
\end{abstract}

Keywords: Mg alloys; twin nucleation and growth; solid solution hardening; micropillar compression; plastic anisotropy.

* Corresponding author: javier.1lorca@imdea.org (J. LLorca)

Acta Materialia, accepted for publication.

February 2020 


\section{Introduction}

Magnesium and its alloys have attracted significant interest recently for engineering applications in automotive, aerospace, electronics, and biomedical sectors due to their low density, high specific-stiffness, superior damping capacity and biocompatibility [15]. Mg alloys have a hexagonal closed packed (HCP) lattice structure and plastic deformation in $\mathrm{Mg}$ alloys tends to be localized along the basal plane because the critical resolved shear stress (CRSS) for $<a>$ basal slip is around $\sim 0.5 \mathrm{MPa}$ [6-8]. Deformation perpendicular to the basal plane cannot be easily accommodated by $<c+a>$ pyramidal slip at room temperature because the CRSS for pyramidal slip is very high ( $\sim 0 \mathrm{MPa}[9])$ and tensile twinning $\{10 \overline{1} 2\}<10 \overline{1} 1>$, that is activated at low values of the CRSS $(\sim 12 \mathrm{MPa}$ [9]), becomes the second dominant plastic deformation mechanism. Pure Mg is very soft as a result of the low CRSS values for basal slip and twinning and, in addition, twinning is a polar deformation mechanism that is only activated when leading to an extension of the $c$ axis of the HCP lattice. As a result, textured Mg alloys show a strong plastic anisotropy which leads to poor ductility and formability at room temperature, hindering their application in structural elements. Thus, understanding and controlling twinning is of crucial importance to design Mg alloys with improved properties.

Twinning deformation mainly comprises two different processes: twin nucleation and twin growth (thickening). Twin nucleation is heterogeneous and takes place in regions with large stress concentrations in the microstructure, such as grain boundaries [10,11]. Several theories were proposed in the past for twin nucleation, including the pole mechanism of Thompson and Millard [12] and the slip dislocation dissociation mechanism of Mendelson [13]. More recently, twin nucleation has been studied by means of atomistic simulations [10,14-16] and in situ mechanical tests on micropillars [17] and these studies have revealed several dislocation-based structures of twin nuclei. Regarding the twin growth, it is generally accepted that twin thickening is mediated by the glide of twinning dislocations along the twin planes [18], and such migration is controlled by the resolved shear stress on the twin plane and direction.

Tailoring the mechanical properties of $\mathrm{Mg}$ alloys by means of alloying is an obvious strategy that requires a detailed knowledge of the effect of solute atoms on the CRSS of the different plastic deformation mechanisms. This has been achieved for basal slip in Mg-Al and Mg-Zn alloys by means of tests in single crystals [19,20] and micropillar 
compression tests [21]. Regarding solid solution strengthening of tensile twinning, it has been reported that $\mathrm{Y}, \mathrm{Zr}, \mathrm{Nd}$ and $\mathrm{Li}$ increase the CRSS for twinning [22-25], while the effect of $\mathrm{Zn}$ is negligible [26,27]. For instance, the CRSS value to activate tensile twinning in $\mathrm{Mg}$ was increased up to $\sim 100 \mathrm{MPa}$ by the addition of 10 at.\%Y [23], while 5 wt.\%Li improved the CRSS for twinning up to $25 \mathrm{MPa}$ [25]. However, these analyses were carried out in polycrystalline samples and the effect of the alloying elements on the CRSS for twinning was estimated indirectly after it was isolated from other hardening mechanisms (grain boundaries, latent hardening and the influence of the solute atoms on basal, prismatic and pyramidal slip). Moreover, these strategies based on tests in polycrystals cannot distinguish between the effect of solute atoms on the CRSS for twin nucleation and growth.

These limitations can be overcome through the application of micromechanical testing techniques. In fact, micropillar compression tests have been extensively used to analyse the different deformation mechanisms of $\mathrm{Mg}$ and $\mathrm{Mg}$ alloys along specific orientations [17,21,26,28-35], overcoming the limitations of tests in polycrystals. For instance, micropillar compression tests were performed in pure $\mathrm{Mg}$ along the $a$-axis $[17,26,28,30,31,35]$ to explore the effect of the micropillar size on the mechanisms of $\{10 \overline{1} 2\}$ twin deformation and on the CRSS for twin growth. Using these techniques, they estimated CRSSs for twin growth of $\sim 7 \mathrm{MPa}$ [26] and $29 \mathrm{MPa}$ [35] in pure $\mathrm{Mg}$.

In this investigation, micropillar compression tests are used in combination with diffusion couples to analyze the mechanisms of twin nucleation and growth in $\mathrm{Mg}-\mathrm{Al}$ alloys. To this end, micropillars of cross-sections in the range $3 \times 3 \mu \mathrm{m}^{2}$ to $7 \times 7 \mu \mathrm{m}^{2}$ were milled from large grains with different Al content in the diffusion couples and were tested in compression along the [01 $\overline{1} 0]$ orientation. The CRSS values for twin nucleation and growth could be obtained from the stress-strain curves after careful examination of the deformation mechanisms and of the effect of micropillar size. This information, together with the CRSS for basal slip from a previous investigation [21] and for pyramidal slip obtained from micropillar compression tests along [0001], showed that the plastic anisotropy of $\mathrm{Mg}-\mathrm{Al}$ alloys increased with the $\mathrm{Al}$ content.

\section{Material and experimental procedures}

Pure $\mathrm{Mg}$ and $\mathrm{Mg}-9$ at.\%Al alloys were melted and cast in an induction furnace in $\mathrm{Ar}$ from high-purity $\mathrm{Mg}(99.99$ wt.\%) and $\mathrm{Al}(99.99$ wt.\%) pellets. The cast ingots were 
homogenized in Ar within quartz capsules at $673 \mathrm{~K}$ for 15 days and discs of $12 \mathrm{~mm}$ in diameter and $7.5 \mathrm{~mm}$ in length were machined. The surfaces of the pure $\mathrm{Mg}$ and $\mathrm{Mg}-9$ at.\% $\mathrm{Al}$ discs were polished and diffusion-bonded in vacuum under a compression force of $800 \mathrm{~N}$ for $1 \mathrm{~h}$ at $673 \mathrm{~K}$ to create a Mg/Mg-9 at.\%Al diffusion couple, which was annealed in Ar at $673 \mathrm{~K}$ during $352 \mathrm{~h}$ to obtain the composition gradient and release the thermal stresses. More details of the process to manufacture the diffusion couple can be found in [21].

Square samples of $7 \times 7 \mathrm{~mm}^{2}$ and $2 \mathrm{~mm}$ in thickness were cut from the diffusion couple perpendicular to the bonding interface and chemically polished to remove any residual surface damage. Afterwards, the composition profiles perpendicular to the bonding interface within the diffusion region were measured by the electron probe microanalysis (EPMA) using Wavelength Dispersive Spectroscopy (WDS) with a voltage of $20 \mathrm{kV}$ and a beam current of $50 \mathrm{nA}$ in a JEOL Superprobe JXA-8900M. In addition, the microstructure of the specimens was characterized using electron backscatter diffraction (EBSD) in a dual beam scanning electron microscope (SEM) Helios Nanolab 600i FEI at an accelerating voltage of $30 \mathrm{kV}$ and a beam current of $2.7 \mathrm{nA}$ to identify the grain orientation and the grain size. The grain sizes within the diffusion region were very large $(>1 \mathrm{~mm})$, as shown in [21].

Micropillars with a square cross-section with selected chemical compositions (pure $\mathrm{Mg}, \mathrm{Mg}-4$ at.\%Al and $\mathrm{Mg}-9$ at.\%Al) were fabricated within the interdiffusion region in the centre of grains oriented perpendicularly to the [01 10$]$ orientation. The cross section of the micropillars was varied from $3 \times 3 \mu \mathrm{m}^{2}$ to $5 \times 5 \mu \mathrm{m}^{2}$ to $7 \mathrm{x} 7 \mu \mathrm{m}^{2}$ to explore the effect of the size on the mechanical behaviour. The aspect ratio of the micropillars was in the range 2:1 to 3:1 to avoid buckling while the stress state was uniform along most of the length of the micropillar (Figure 1a) [36,37]. The micropillars were fabricated using a FEI Helios Nanolab 600i FEI focused ion beam (FIB) microscope with a $\mathrm{Ga}^{+}$ion beam operated at $30 \mathrm{kV}$. The initial beam current was $9.3 \mathrm{nA}$ and it was reduced to $40 \mathrm{pA}$ in the final polishing step to minimize the surface damage due to the $\mathrm{Ga}^{+}$ion implantation. Moreover, the sample was tilted $\pm 2^{\circ}$ with respect to the ion beam axis during the final milling to reduce the taper, which was always below $1^{\circ}$ (Figure 1a).

Micropillar compression tests were carried out using a TI950 Triboindenter (Hysitron, Inc., Minneapolis, MN) equipped with a diamond flat punch with a diameter of $15 \mu \mathrm{m}$. All the tests were carried out at a constant strain rate of $10^{-3} \mathrm{~s}^{-1}$ under the displacement control up to a maximum strain of $10 \%$. The load-displacement curves were corrected by 
applying the Sneddon method [38,39] to account for the compliance associated with the elastic deflection of the base of the micropillar. The engineering stress-strain curves were obtained from the corrected curves from the cross-sectional area and the height of the micropillar before deformation. At least three tests were repeated for each condition (alloy composition and micropillar size) to ensure the reproducibility of the results. It has been shown that the mechanical properties measured with square-section micropillars are equivalent to those obtained with circular ones [40]. It should be noted that ex situ micropillar compression tests were selected to analyse the mechanical behaviour instead of in situ tests [21] because the only additional information provided by the in situ tests (with respect to the ex situ tests) is the continuous imaging of the two external surfaces of the micropillar. But twin nucleation and growth may occur within the micropillar without modifying the observed external surfaces.

After the compression tests, the morphology of the deformed micropillars was carefully examined using secondary electrons in the SEM. In addition, transmission Kikuchi diffractiob (TKD) and transmission electron microscopy (TEM) were used to characterize the deformation mechanisms for selected micropillars. To this end, thin lamella of the cross-sections of the deformed micropillars were extracted using the standard lift-out technique [41] in the FEI Helios 600 FIB microscope at $30 \mathrm{kV}$. The lamella was thinned to approximately $100 \mathrm{~nm}$ by adopting a range of ion beam currents from $2.5 \mathrm{nA}$ to $40 \mathrm{pA}$ and finally polished at $5 \mathrm{kV}$ with an ion beam current of $15 \mathrm{pA}$ to minimize the $\mathrm{Ga}^{+}$ion beam damage. The TKD mapping was carried out in the Helios Nanolab 600i FEI microscope equipped with an Oxford Instruments NordlysNano EBSD detector. The electron beam was operated at $15 \mathrm{kV}$ with a beam current of $2.7 \mathrm{nA}$ and the TKD maps were collected with a step size of $50 \mathrm{~nm}$. The TEM observations were performed in a Talos F200X microscope at an accelerating voltage of $200 \mathrm{kV}$.

\section{Results}

\subsection{Deformation mechanisms of pure Mg during [01̄̄0] compression}

The micropillars were deformed parallel to the [01 $\overline{10}$ ] orientation of the $\mathrm{Mg}$ lattice. The experimental values of the CRSS of the different deformation modes of pure $\mathrm{Mg}$ under compression in the literature $[6-9,42,43]$ are summarized in Table 1, together with the corresponding Schmid factors $(m)$ for compression along the [0110], [011 6$]$ and [0001] orientations. The second orientation corresponds to the lattice orientation after 
$\{10 \overline{1} 2\}$ tensile twinning, while [0001] direction was selected to study pyramidal slip. The Schmid factor for all the slip systems and tensile twinning were computed based on the crystal orientation information obtained from the EBSD measurements following the protocol in [44].

Although the CRSS for basal slip is very low $(\approx 0.5 \mathrm{MPa})$, this mechanism is not expected to be dominant in the micropillar oriented along the [01 $\overline{1} 0]$ orientation because the Schmid factor for basal slip is almost zero. $\{10 \overline{1} 2\}$ tensile twinning shows the highest Schmid factor $(0.48-0.49)$, followed by prismatic slip $(0.46)$. However, the CRSS for prismatic slip is much higher than that of tensile twinning and, therefore, $\{10 \overline{1} 2\}$ tensile twinning is expected to be the preferred deformation mode under [011 0 ] compression. It is worth noting that two twin variants have very high Schmid factors and, thus, they have similar probabilities to develop during deformation.

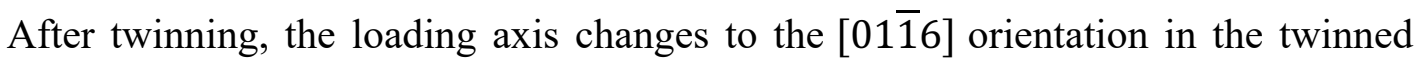
region as a result of the crystal reorientation by $\sim 86^{\circ}$, which is schematically shown in Fig. 1b. The new compression direction has a misorientation $\sim 5^{\circ}$ with respect to [0001] crystal orientation [26,30], and the Schmid factors for all deformation modes in the twinned region are listed in Table 1. Since the new compression axis is quite close to the [0001] orientation, the active deformation mechanisms may be expected to be similar to the ones found during compression along the [0001] orientation [30,32,33].
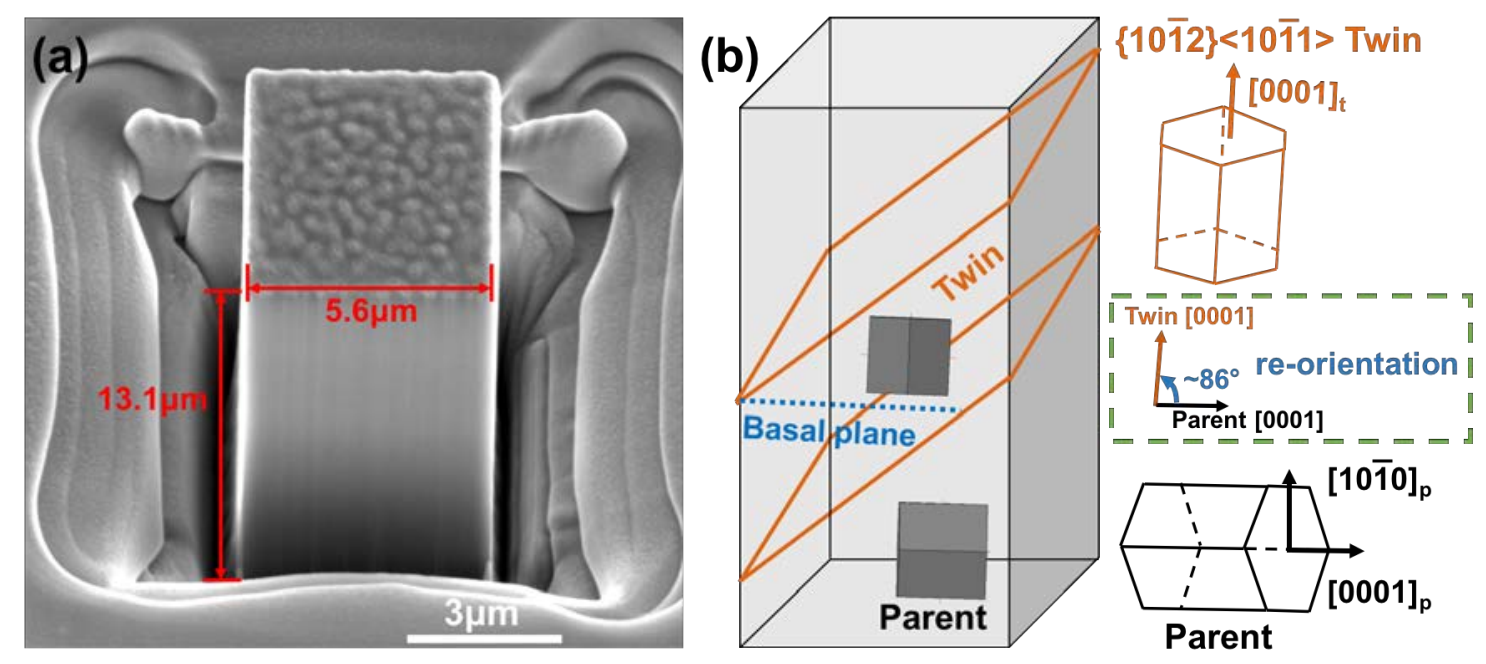

Fig. 1. (a) Representative micropillar of $5 \times 5 \mu \mathrm{m}^{2}$ cross-section. (b) Schematic of the orientation relationship between the parent and twin regions in the micropillar. The parent crystal is reoriented by $\sim 86^{\circ}$ by twinning. 
A representative engineering stress-strain curve is plotted in Fig. 2 from the compression test of a micropillar of pure $\mathrm{Mg}$ of $5 \times 5 \mu \mathrm{m}^{2}$ cross-section. The initial linear elastic response is abruptly finished by an abrupt load drop followed by a strain burst. Afterwards, the deformation progresses at constant stress up to an applied strain of $5.5 \%$ when the micropillar shows a very high strain hardening up to the maximum applied strain of $10 \%$. The different regions in the stress-strain curve are expected to correspond to different dominant deformation mechanisms and, thus, various tests were stopped after the first load drop $(\varepsilon \approx 1 \%)$, at the end of the plateau region $(\varepsilon \approx 6 \%)$ and at $\varepsilon \approx 10 \%$ to analyze the microstructure. The corresponding points are marked with (b), (c) and (d), respectively, in Fig. 2 a.

Table 1. Critical resolved shear stress (CRSS) and Schmid factor $(m)$ of the possible deformation

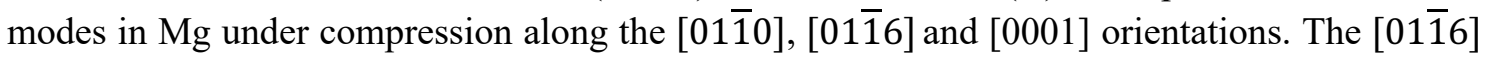
orientation corresponds to the crystal orientation after twinning.

\begin{tabular}{lccccc}
\hline Deformation mode & CRSS (MPa) & \multicolumn{3}{c}{ Schmid factor $(m)$} \\
\cline { 3 - 5 } & & & {$[01 \overline{1} 0]$} & {$[01 \overline{1} 6]$} & {$[0001]$} \\
\hline Basal & $(0001)[11 \overline{2} 0]$ & $0.5[6-8]$ & 0 & 0.13 & 0.03 \\
& $(0001)[1 \overline{2} 10]$ & & 0 & 0.12 & 0.05 \\
& $(0001)[\overline{2} 110]$ & & 0 & 0.02 & 0.02 \\
\hline Prismatic & $(1 \overline{1} 00)[1 \overline{1} 0]$ & $39[42]$ & 0.46 & 0.01 & 0 \\
& $(10 \overline{1} 0)[1 \overline{2} 10]$ & & 0.39 & 0.01 & 0 \\
& $(01 \overline{1} 0)[\overline{2} 110]$ & & 0.07 & 0 & 0 \\
\hline Pyramidal II & $(11 \overline{2} 2)[\overline{11} 23]$ & $80[9]$ & 0.27 & 0.49 & 0.43 \\
& $(\overline{1} 2 \overline{1} 2)[1 \overline{2} 13]$ & & 0.32 & 0.48 & 0.43 \\
& $(1 \overline{2} 12)[\overline{1} 2 \overline{1} 3]$ & & 0.39 & 0.38 & 0.47 \\
& $(\overline{1} 122)[11 \overline{2} 3]$ & & 0.34 & 0.37 & 0.46 \\
& $(2 \overline{1} 12)[\overline{2} 113]$ & & 0 & 0.44 & 0.45 \\
& $(\overline{2} 112)[2 \overline{11} 3]$ & & 0.37 & 0.07 & 0.16 \\
\hline \multirow{2}{*}{$10 \overline{1} 2\}$ twin } & $(10 \overline{1} 2)[\overline{1} 011]$ & $12[43]$ & 0.09 & 0.48 & -0.49 \\
& $(1 \overline{1} 02)[\overline{1} 101]$ & & 0.15 & 0.49 & -0.49 \\
& $(01 \overline{1} 2)[0 \overline{1} 11]$ & & 0.49 & 0.47 & -0.50 \\
& $(0 \overline{1} 12)[01 \overline{1} 1]$ & & 0.48 & 0.49 & -0.49 \\
& $(\overline{1} 012)[10 \overline{1} 1]$ & & 0.09 & 0.49 & -0.49 \\
& $(\overline{1} 102)[1 \overline{1} 01]$ & & 0.15 & 0.48 & -0.50 \\
\hline
\end{tabular}

The observation of the micropillar in the SEM after the sudden load drop at $1 \%$ strain (Fig. 2b) showed a slight tilt along the edge of the lateral surface (marked with an arrow). A thin lamella was extracted from the deformed micropillar and characterized by TKD. This analysis showed that the two variants of the $\{10 \overline{1} 2\}$ twin (T1 and T2) with the 
highest Schmid factor were nucleated in the upper part of the micropillar (Fig. 2e), leading to $\mathrm{a} \sim 86^{\circ}$ rotation from the parent lattice. The crystal orientation of both twinning variants and of the parent are schematically shown in Fig. $2 \mathrm{~g}$. The twin boundary (TB) and the boundary between the two twin variants (TTB) were marked by black and yellow lines, respectively, in Fig 2(e). Thus, the load drop was associated with the crystal reorientation induced by the nucleation of two $\{10 \overline{1} 2\}$ twin variants.
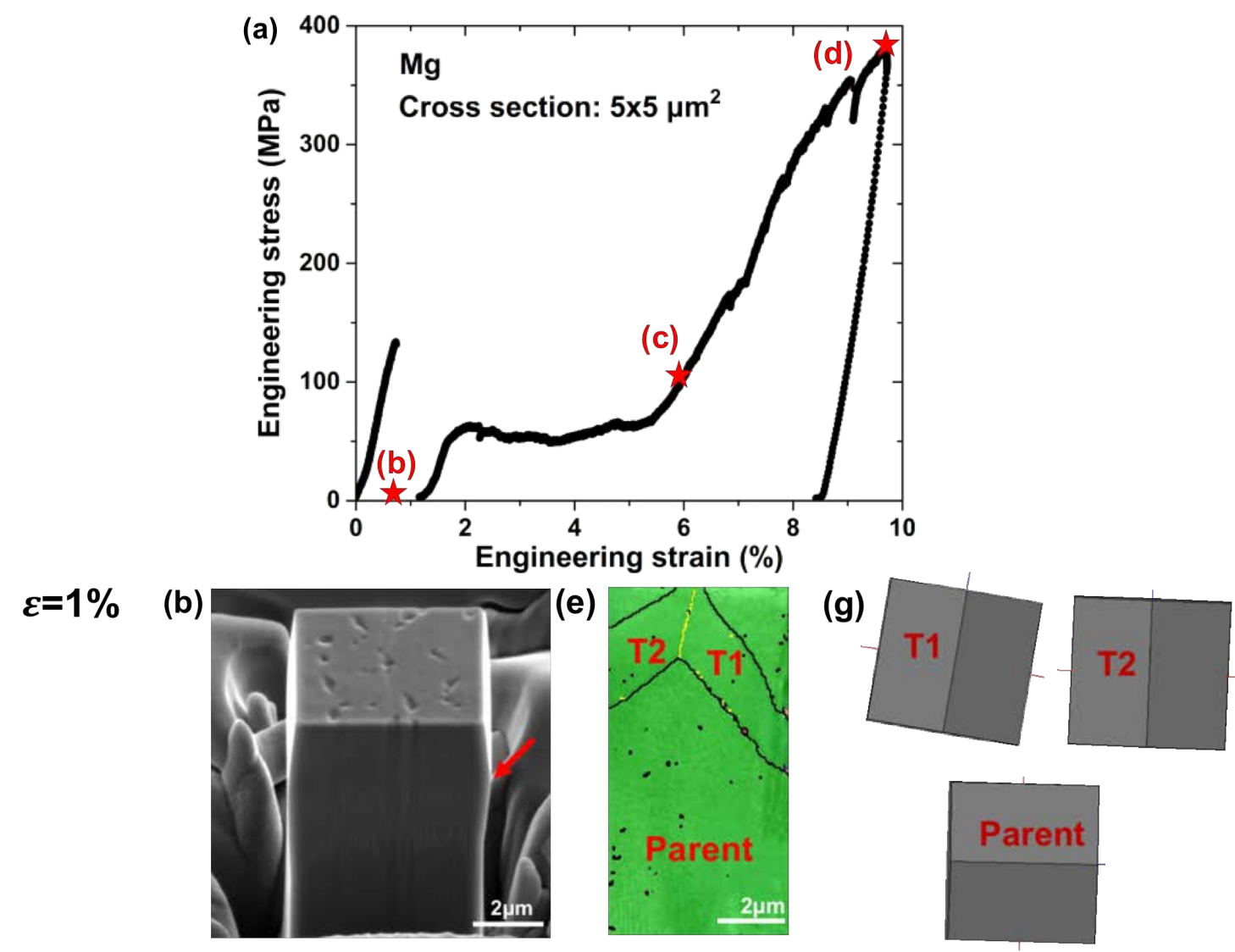

$\varepsilon=6 \%$

(c)

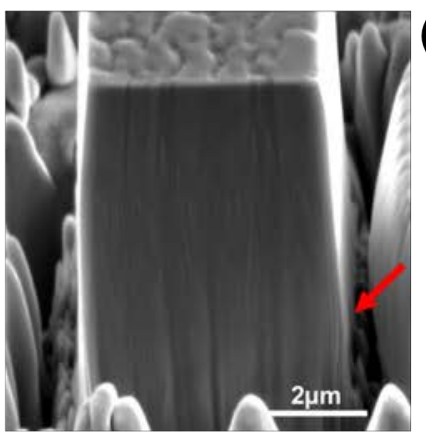

$\varepsilon=10 \% \quad(d)$ (f)

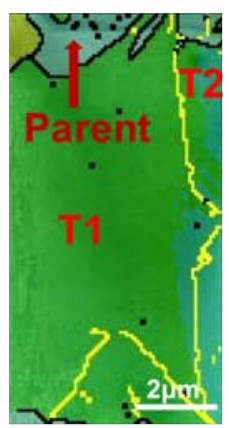

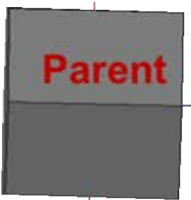

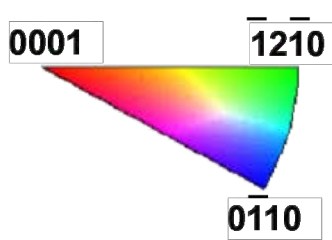

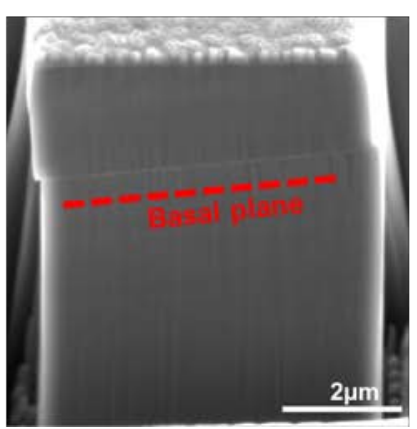


Fig. 2. (a) Representative engineering stress-strain curve of a pure Mg micropillar of $5 \times 5 \mu \mathrm{m}^{2}$ deformed in compression along the [0110] orientation. (b) SEM micrograph of the deformed micropillar after the load drop at $\sim 1 \%$ strain. (c) Idem at $6 \%$ strain. (d) Idem at $10 \%$ strain. (e-f) $t$-EBSD maps of a thin lamella extracted from the deformed micropillars in (b-c). (g) Schematic of the HCP lattice orientation in both twin variants and in the parent crystal. Black and yellow lines in (e-f) stand for the twin boundary (TB) and the boundary between the two twin variants (TTB).

After twin nucleation, the flow stress remained constant up to an applied strain of $\approx 5.5 \%$. The SEM micrograph of another micropillar deformed up to $6 \%$ shows that the tilt feature along the lateral edge has propagated up to the bottom of the micropillar (Fig. 2c) and the orientation map obtained by TKD of another lamella extracted from the micropillar is shown in Fig. 2f. It confirmed that the whole micropillar was twinned by the thickening of both twin variants that took place at constant stress.

Another micropillar was tested up to an applied strain of $10 \%$, and the SEM micrograph of the deformed micropillar showed the presence of slip traces parallel to the basal plane of the twinned crystal on the lateral surface (Fig. 2d). Although the orientation within the twinned region is not favourably oriented for basal slip $\left(\sim 8^{\circ}\right.$ misorientation with respect to the $c$-axis), slip traces were found on the lateral surface of the micropillar (Fig. 2d) because the applied stress was very large (close to $400 \mathrm{MPa}$ ) and the CRSS for basal slip is quite low.

In order to further investigate the deformation mechanisms, the lamella extracted from the micropillars deformed up $6 \%$ and $10 \%$ were examined by TEM. A reduced number of $\langle a\rangle$ dislocations are observed within the parent crystal on the prismatic plane in the micropillar deformed up to $6 \%$, as shown in Fig. 3a under the diffraction condition of $g=[01 \overline{1} 1]_{\mathrm{p}}$. Although the CRSS value for prismatic slip is very high (Table 1$)$, it is possible that prismatic slip was activated taking into account the compressive stress attained to nucleate the twin and the Schmid factor of some prismatic slip systems [30,44]. Nevertheless, their contribution to the plastic slip should be small taken into account the small density of these dislocations. A few dislocations were also observed on non-basal planes in the vicinity of the twin boundary within the twinned region with a $\left\langle_{c}\right\rangle$ component when the applied strain was $6 \%$ (Fig. 3b). At the $g=[0002]_{\mathrm{t}}$ diffraction condition, the visible dislocations have a Burgers vector with a $\langle c>$ component based on the dislocation extinction criterion, and they may be $\left\langle_{c}\right\rangle$ or $\left\langle_{c}+a\right\rangle$ dislocations. The density of these dislocations increased dramatically when the applied strain reached $10 \%$, as shown in Fig. $3 \mathrm{c}$. When the diffraction condition is changed to $g=[01 \overline{1} 1]_{\mathrm{t}}$, dislocations 
containing an $\langle a\rangle$ component could be revealed and more dislocations are observed under $g=[01 \overline{1} 1]_{\mathrm{t}}$ in Fig. 3d, confirming the presence of the dislocations with Burgers vector $\langle c+a\rangle$. The large density of $\langle c+a\rangle$ dislocations in the prismatic plane within the twinned region, associated to the large strain hardening of the stress-strain curve, indicates that pyramidal slip was progressively activated within the twinned micropillar for applied strains $>6 \%$ and become the dominant plastic deformation mechanism once the whole micropillar was twinned. This statement will be supported by additional evidence presented in section 4.3.

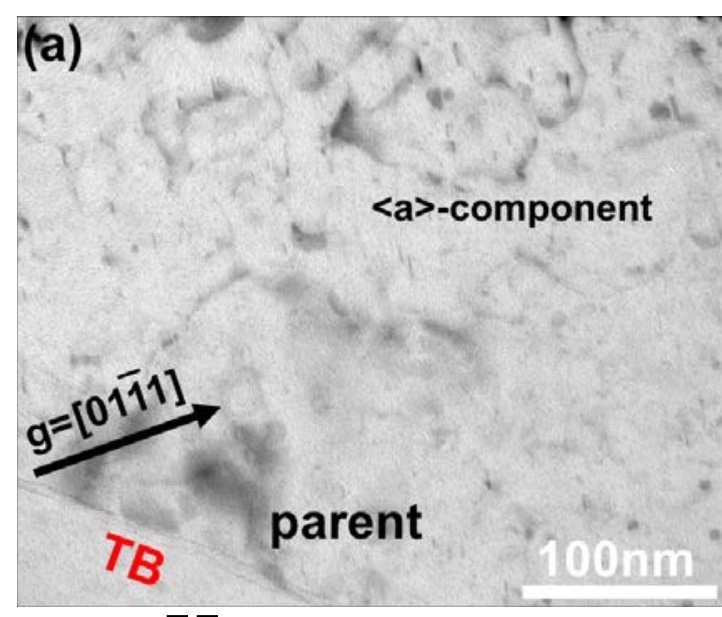

\section{Zone:[2 $\overline{1} \overline{1} 0]$}

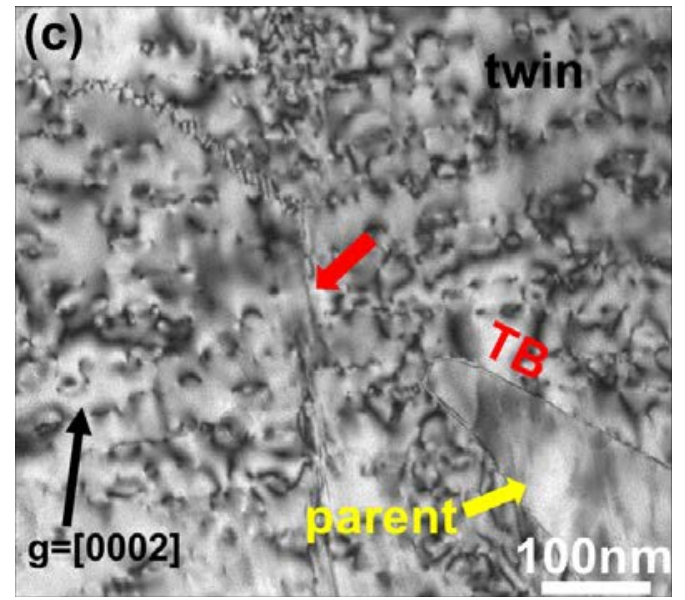

\section{Zone:[2 $\overline{1} \overline{1} 0]$}

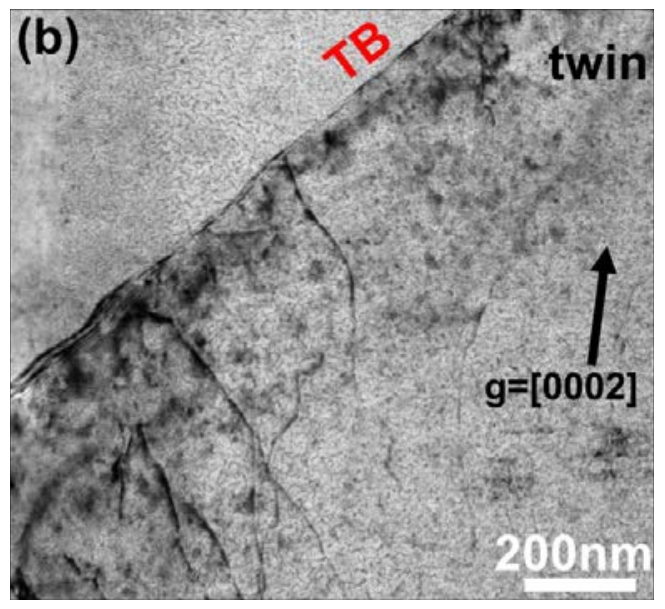

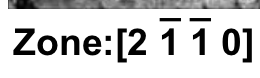

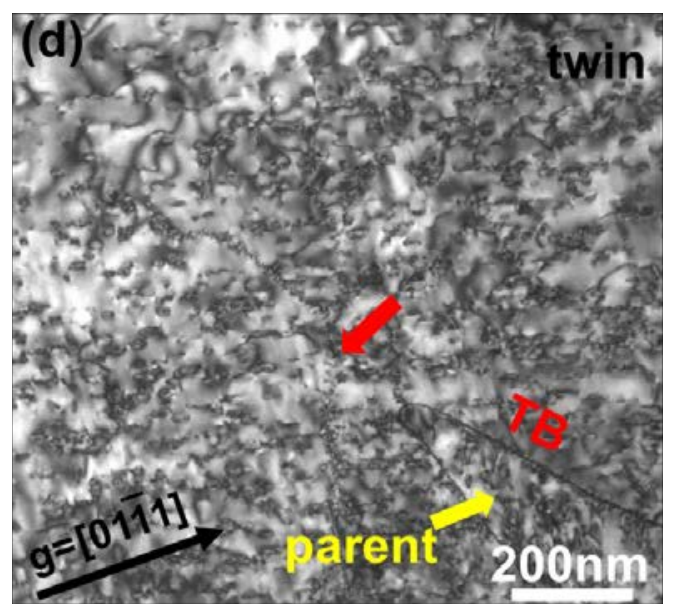

\section{Zone:[2 $\overline{1} \overline{1} 0]$}

Fig. 3. TEM micrographs of lamella extracted from micropillars deformed up to different strains. (a) Applied strain $6 \%$. $<a>$ dislocations in the prismatic plane within the parent region, $g=[01 \overline{1} 1]_{\mathrm{p}}$. (b) Applied strain $6 \% .<c>$ dislocations in the twinned region, $g=[0002]_{\text {t. }}$ (c) Applied strain $10 \%$. $<c>$ dislocations in the twinned region, $g=[0002]_{\text {t. }}$ (d) Same as (c) but observed under the $g=[01 \overline{1} 1]_{\mathrm{t}}$, confirming the presence of $\langle a+c\rangle$ dislocations in this region. The zone axis was $[2 \overline{1} \overline{1} 0]$ in all cases.

In this investigation, the twin nucleation stress was determined from the critical point of load drop (associated with the formation of twin), while the twin growth stress was 
corresponding to the stress-plateau that was associated with the migration of the twin boundaries, as stated above. The magnitude of the critical stresses for twin nucleation and growth are consistent with the results of Wang. et al. [26], who tested Mg micropillars in compression oriented for twinning. Some of the micropillars were twin-free while others contained twins and, thus, the critical stresses for twin nucleation and growth were determined in different micropillars. In our case, both magnitudes were determined from a single test in a twin-free micropillar.

\subsection{Deformation mechanisms of $\mathrm{Mg}$-Al alloys during [01 $\overline{10}$ ] compression}

A representative engineering stress-strain curve of a micropillar of $7 \times 7 \mu \mathrm{m}^{2}$ is plotted in Fig. 4a for a Mg-9 at.\%Al alloy. The micropillar was milled in another grain with the same $[01 \overline{1} 0]$ oreintation and the general features of the curve were similar to those reported for pure $\mathrm{Mg}$ (Fig. 2a). A pronounced load drop took place at 1\% elastic strain and was accompanied by a strain burst up to $3 \%$ strain which was associated with twin nucleation at the upper region of the micropillar. Deformation progressed at constant stress afterwards, followed by a step hardening region for strains $>5 \%$. The stress carried by the micropillar at $10 \%$ was close to $600 \mathrm{MPa}$, much higher than the one in the case of pure $\mathrm{Mg}(\approx 400 \mathrm{MPa})$. Moreover, strain bursts (that can be noticed by sudden drops in the load during deformation) were found in the plateau and hardening regions of the $\mathrm{Mg}$ 9 at.\% $\mathrm{Al}$ alloy but not in the case of the pure $\mathrm{Mg}$ micropillars.

Micropillar compression tests were stopped at $1 \%$ strain, after the sudden load drop, and at $10 \%$ strain to further analyze the deformation mechanisms. The micropillar deformed up to $1 \%$ showed a slight tilt along the edge of the lateral surface (Fig. 4b), as in the case of pure $\mathrm{Mg}$. A thin lamella was extracted from the micropillar and characterized by TEM. The twinned region occupied the upper part of the whole pillar, and two TBs can be found in Fig. 4d. They were parallel to the twin plane, indicated by the red dotted line. Moreover, the TTB between the two $\{10 \overline{1} 2\}$ twin variants (T1 and T2) is marked by the yellow dashed line in Fig. 4d. The presence of the twin and of the parent were explicitly confirmed by the diffraction patterns.

The lateral surface of the micropillar deformed up to $10 \%$ also showed slip traces parallel to the basal plane of the twinned crystal (Fig. 4c). The TKD image of a lamella extracted from this micropillar showed that the whole micropillar has been twinned and one of the twin variants has propagated and replaced the other variant (Fig. 4e), which was only found at the bottom-right corner of the micropillar. The crystal orientation of 
the twin variants and of the parent are shown in Fig. 4f. Similar to the case of pure $\mathrm{Mg}$, one twin variant grew at the expense of the other variant during deformation. The slip traces and the slip steps corresponding to the basal plane in the twinned crystal were more marked than in pure $\mathrm{Mg}$ (Fig. 4c) and they were responsible for the strain bursts observed in Fig. 4a during strain hardening.

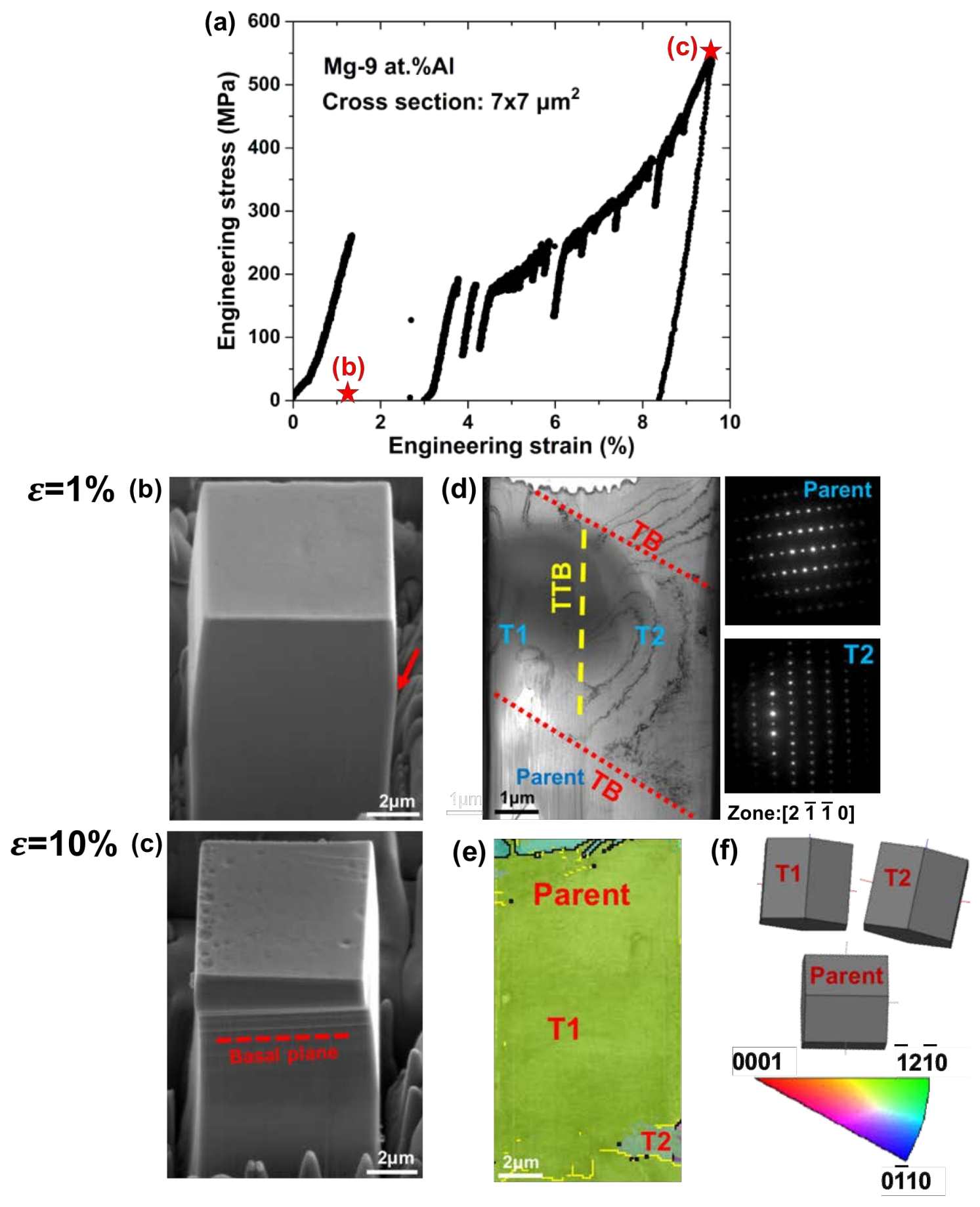

Fig. 4 (a) Representative engineering stress-strain curve of a Mg-9 at.\%Al micropillar of 7x7 $\mu \mathrm{m}^{2}$ deformed in compression along the $[01 \overline{1} 0]$ orientation. (b) SEM micrograph of the deformed micropillar after the load drop at $\sim 1 \%$ strain. (c) Idem at 10\% strain. (d) TEM micrograph of the thin lamella extracted from the micropillar in (b), including the diffraction patterns of the parent 
and twin regions. (e) TKD maps of a thin lamella extracted from the micropillar in (c). Black and yellow lines stand for the twin boundary (TB) and the boundary between the two twin variants (TTB). (f) Schematic of the HCP lattice orientation in both twin variants and in the parent crystal.

The dislocation structure within the parent and twinned regions was analysed by TEM. Prismatic $\langle a\rangle$ dislocations in the parent region (Fig. 5a) as well as pyramidal $\langle c+a\rangle$ dislocations in the twinned region (Fig. 5b) were found in the micropillar deformed up to $1 \%$, as in the case of pure Mg. The density of pyramidal $<_{c}+a>$ dislocations in the twinned region increased when the micropillar was deformed up to $10 \%$ (Fig. 5c) but the dislocation density was significantly lower than in the case of pure $\mathrm{Mg}$. These differences are obviously related to the higher strain hardening of the $\mathrm{Mg}-9$ at.\%Al micropillars and they will be analysed in more detail below.

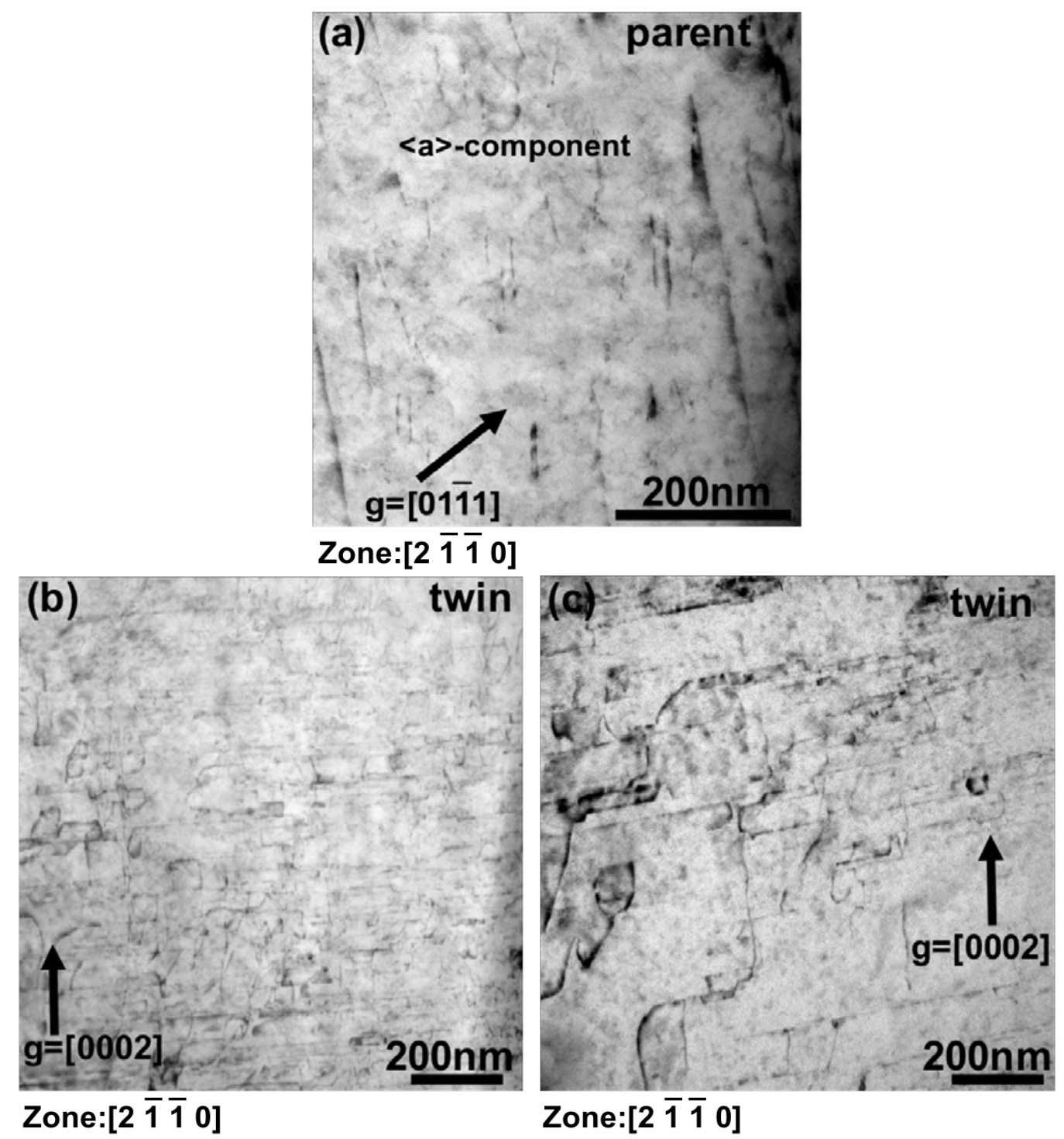

Fig. 5. (a) Applied strain 1\%. $\langle a>$ dislocations in the prismatic plane within the parent region, $g=[01 \overline{1} 1]_{\mathrm{p}}$. (b) Applied strain $1 \% .<c>$ dislocations in the twinned region, $g=[0002]_{\mathrm{t}}$. (c) Applied 
strain $10 \% .<c>$ dislocations in the twinned region, $g=[0002]$ t. The zone axis was $[2 \overline{1} \overline{1} 0]$ in all cases.

\subsection{Size effects during [011̄0] compression of $\mathrm{Mg}$ and $\mathrm{Mg}$-Al alloys}

The engineering stress-strain curves of the compression tests of micropillars of pure $\mathrm{Mg}, \mathrm{Mg}-4$ at.\%Al and $\mathrm{Mg}-9$ at.\%Al with different lateral cross-section (in the range $3 \times 3 \mu \mathrm{m}^{2}$ to $7 \times 7 \mu \mathrm{m}^{2}$ ) are plotted in Figs. $6 \mathrm{a}, \mathrm{b}$ and $\mathrm{c}$, respectively. The three regions analysed in the previous sections were found in all cases, regardless of the micropillar size and $\mathrm{Al}$ content. The critical stress for twin nucleation was higher in the $3 \times 3 \mu \mathrm{m}^{2}$ micropillars but no differences were found between $5 \times 5 \mu \mathrm{m}^{2}$ and $7 \mathrm{x} 7 \mu \mathrm{m}^{2}$ micropillars.
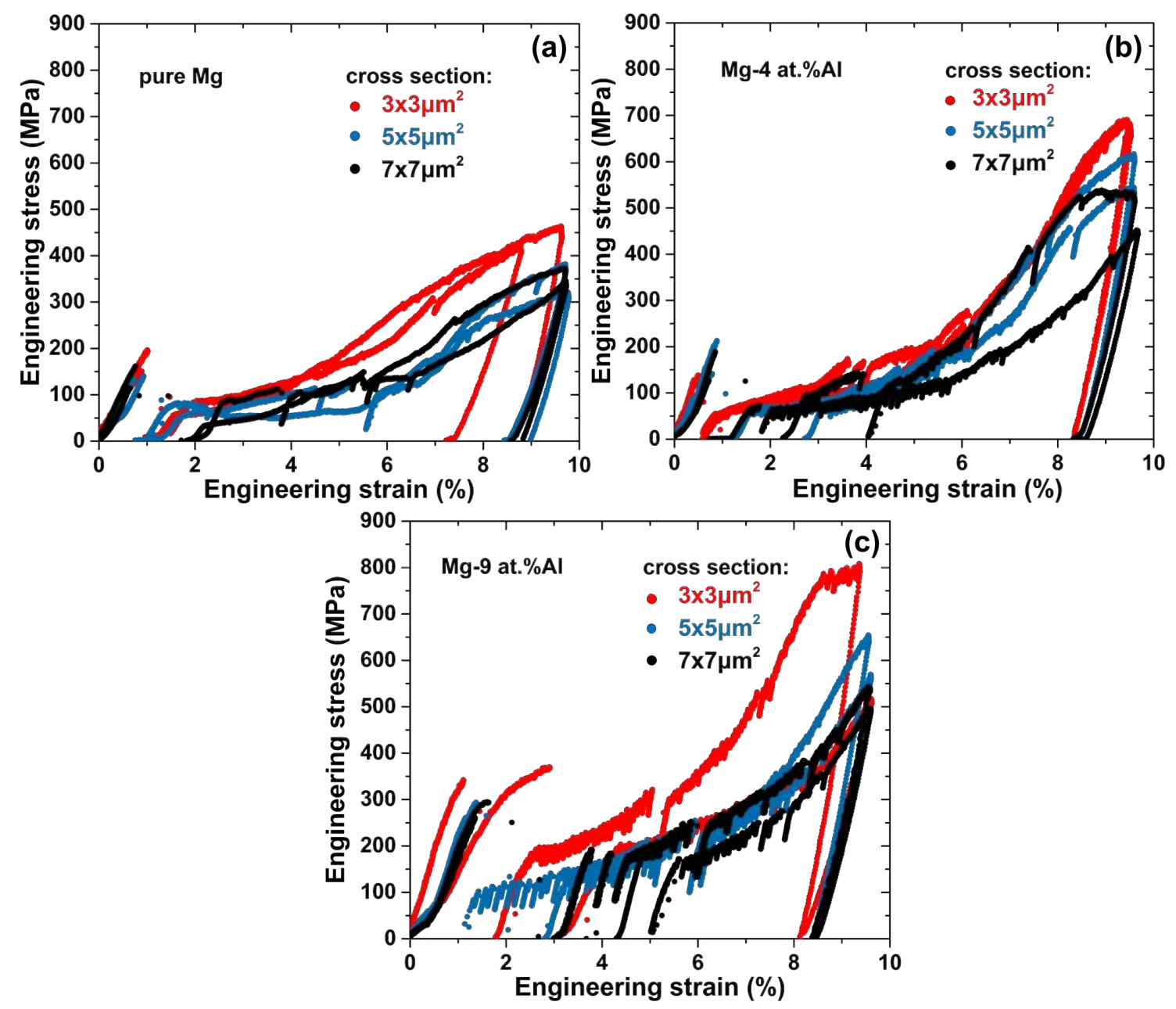

Fig. 6 Representative engineering stress-strain curves of micropillar compression tests along [0110] direction in micropillars with lateral cross section in the range $3 \times 3 \mu \mathrm{m}^{2}$ to $7 \times 7 \mu \mathrm{m}^{2}$. (a) Pure Mg, (b) Mg-4 at.\%Al alloy and (c) Mg-9 at.\%Al alloy.

The constant stress plateau after twin nucleation, that was associated to the propagation of one dominant twin variant, was again slightly higher in the $3 \times 3 \mu \mathrm{m}^{2}$ 
micropillars of pure $\mathrm{Mg}$, as compared with larger micropillars. However, these differences were not found in the $\mathrm{Mg}$-Al micropillars. Finally, a size effect was also found in the strain hardening region for applied strains $>5 \%$ in the case of $3 \times 3 \mu \mathrm{m}^{2}$ micropillars of $\mathrm{Mg}$ and $\mathrm{Mg}-\mathrm{Al}$ alloys. However, no significant differences were found in the strain hardening of the larger micropillars. It should also be noticed that the macroscopic shape of the micropillars after testing was independent of the micropillar size and Al content. Slip traces parallel to the basal plane of the twinned crystal were always present (Fig. 7) and everything indicates that the dominant deformation mechanisms were not modified by the micropillar dimensions.
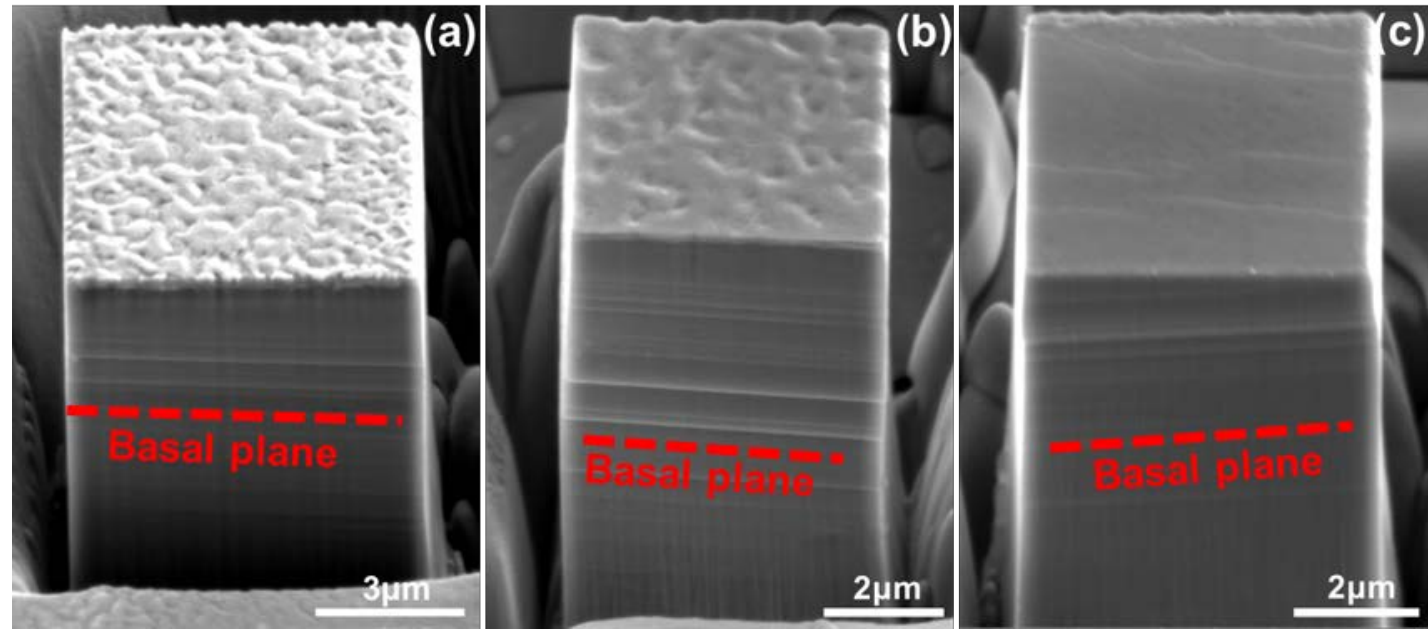

Fig. 7 SEM micrographs of the $5 \times 5 \mu^{2}$ micropillars deformed up to $10 \%$. (a) pure $\mathrm{Mg}$, (b) $\mathrm{Mg}$ 4 at.\%Al alloy and (c) Mg-9 at.\%Al alloy. Slip traces along the basal plane of the twinned region are indicated by the red dash lines.

\section{Discussion}

\subsection{Effect of the micropillar size on the CRSS for twin nucleation and growth}

It is well-known that critical stress for dislocation slip [21,30-32,35,46] as well as twin nucleation and growth $[17,26,28-31,35,47-50]$ increase as the micropillar size decrease. Thus, the analysis of this size effect is mandatory to assess the ability of the micropillar compression tests to provide accurate information about the influence of the solute atoms on the critical stress for twin nucleation and growth. The average values and standard deviation of the critical shear stresses for $\{10 \overline{1} 2\}$ twin nucleation, $\tau_{n}$, and growth, $\tau_{g}$, for pure $\mathrm{Mg}, \mathrm{Mg}-4$ at.\%Al and $\mathrm{Mg}-9$ at.\%Al alloys are plotted as a function of micropillar size in Figs. 8(a) and 8(b), respectively. The twin nucleation stress $\left(\tau_{n}\right)$ is defined as the resolved shear stress on the twin plane at the peak stress associated to the 
twin nucleation. The twin growth stress $\left(\tau_{g}\right)$ stands for the shear stress resolved on the twin plane in the beginning of the plateau region, after the load drop due to the strain burst associated with the nucleation of the twin.
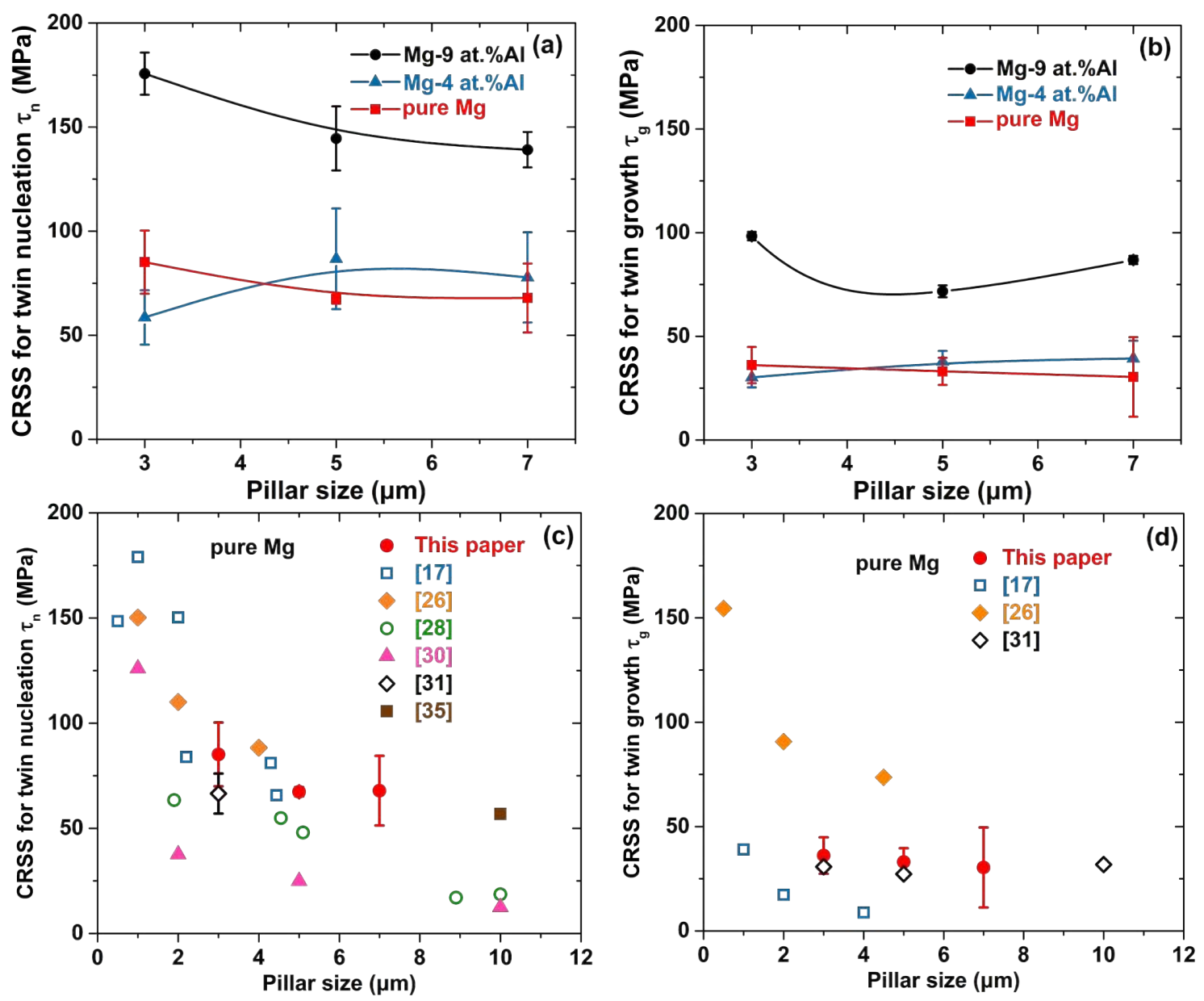

Fig. 8 (a) CRSS for twin nucleation $\left(\tau_{n}\right)$ as a function of the micropillar lateral dimension and Al content. (b) CRSS for twin growth $\left(\tau_{g}\right)$ as a function of the micropillar lateral dimension and $\mathrm{Al}$ content. (c-d) Effect of micropillar dimension on the CRSS for twin nucleation and growth for pure Mg. Results from this investigation and from the literature [17,26,28,30,31,35].

A size effect of the type 'smaller is stronger' was found in the CRSS for twin nucleation in the micropillars of $3 \times 3 \mu \mathrm{m}^{2}$ of $\mathrm{Mg}$ and Mg-9 at.\%Al. Nevertheless, the values of $\tau_{n}$ were similar for micropillars of $5 \times 5 \mu \mathrm{m}^{2}$ and $7 \mathrm{x} 7 \mu \mathrm{m}^{2}$, regardless of the $\mathrm{Al}$ content. In the case of the CRSS for twin growth, a size effect was only found in the micropillars of $3 \times 3 \mu \mathrm{m}^{2}$ of Mg-9 at.\%Al and no significant differences in $\tau_{g}$ were found for $\mathrm{Mg}$ and $\mathrm{Mg}-4$ at.\% $\mathrm{Al}$ as a function of the micropillar dimensions. In the case of pure $\mathrm{Mg}$, the experimental values of $\tau_{g}$ and $\tau_{n}$ have been plotted in Figs. $8 \mathrm{c}$ and $8 \mathrm{~d}$ as a function of the micropillar lateral dimension together with those available in the literature. They show large differences in the critical stress values among different investigations 
but the size effects for both twin nucleation and growth are normally limited to micropillars with lateral dimensions below $3 \mu \mathrm{m}$. The large differences in the CRSS can be attributed to the localized nature of the twin nucleation, which is triggered at the contact point between the flat punch and the micropillar upper surface. Small misalignments (which are very difficult to correct) can lead to large differences in the measured critical stress. Overall, the experimental data for pure $\mathrm{Mg}$ obtained in this investigation are consistent with most of the results in the literature.

\subsection{Effect of Al content on the CRSS for twin nucleation and growth}

As the effect of the micropillar dimensions on the critical shear stress for twin nucleation and growth was negligible for micropillars of $5 \times 5 \mu \mathrm{m}^{2}$ and $7 \times 7 \mu \mathrm{m}^{2}$ crosssection, the values measured with the latter were used to assess the effect of $\mathrm{Al}$ content on them. They are plotted in Fig. 9a and the CRSS for twin nucleation approximately 80 $\mathrm{MPa}$ higher than that for twin growth, regardless of the Al content. The hardening contribution due to the presence of $\mathrm{Al}$ atoms in the CRSS for twin nucleation and growth, expressed as $\Delta \tau_{n}=\tau_{n}(A l)-\tau_{n}(0)$ and $\Delta \tau_{g}=\tau_{g}(A l)-\tau_{g}(0)$, is plotted in Fig. 9b.

Twin thickening is a process mediated by the propagation of twinning dislocations and the solute strengthening was analysed by Ghazisaeidi et al. [51] using a modified version of Labusch model [52] that takes into account that a straight dislocation bows out in the glide plane to minimize the potential energy in the presence of a random solute distribution. The interaction energy between the solute atoms with the twin dislocation (and also with the twin boundary) was determined form first principles calculations, leading to a linear dependence of the CRSS with the Al content for a given value of the strain rate and temperature. The difference with the traditional Labusch model, that predicts that the yields scales with the solute atom concentration to the power of $2 / 3$, is due to the small Burgers vector of the twinning dislocation and to the solute-twin boundary interaction, that provides the main contribution to the strengthening. The predictions obtained from eq. (8) in [51] for ambient temperature and a strain rate of $10^{-}$ ${ }^{3} \mathrm{~s}^{-1}$ are plotted in Fig. 9b. They are in good agreement with the experimental results for Mg-4 at.\%Al but underestimate the experiments for Mg-9 at.\%Al. The origin of these differences may be found in that the energy interaction between the solute atoms and the twin dislocation and the twin boundary was calculated using a dilute approximation, that might not be accurate when the $\mathrm{Al}$ content is 9 at.\%. 

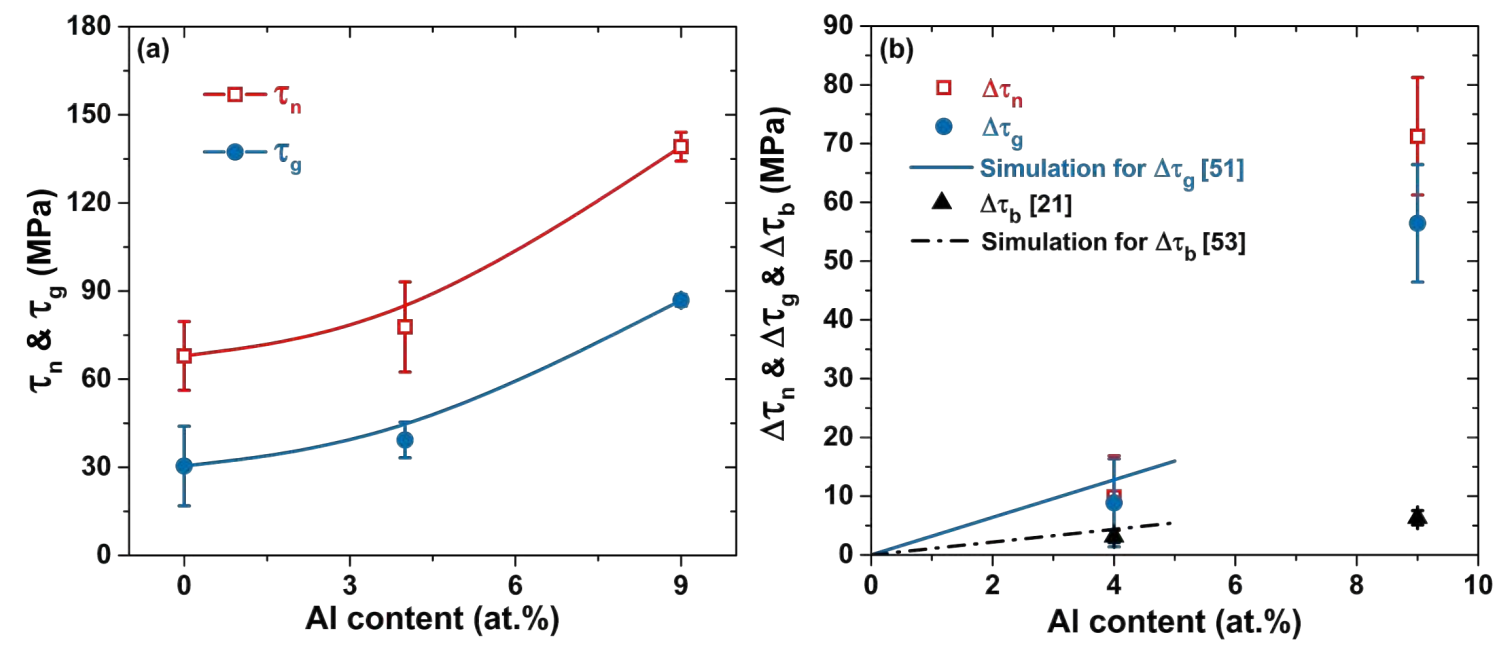

Fig. 9 (a) CRSS for twin nucleation, $\tau_{n}$, and growth, $\tau_{g}$, measured in micropillars of $7 \mathrm{x} 7 \mu \mathrm{m}^{2}$ cross-section as a function of Al content. (b) Increase of the CRSS for twin nucleation, $\tau_{n}$, and growth, $\tau_{g}$, as a function of the Al content. Experimental data of the increase of CRSS for basal slip [21] and the first-principle predictions of the effect of Al content on the CRSS for twin growth [51] and basal slip [53] are also plotted for comparison.

The recent experimental data of the influence of Al content on the CRSS for basal slip $\Delta \tau_{b}$ [21], obtained using the same experimental approach, have been plotted in Fig. $9 \mathrm{~b}$ as well, together with the predictions from [53] based on the modified Labusch model. The agreement between experiments and simulations is good up to 4 at. \% Al and the extrapolation of the model to the non-dilute range also seems to be in agreement with the experimental results in the case of basal slip. Moreover, both experimental and simulations show that the strengthening provided by Al solute atoms is higher in the case of twin nucleation and growth than in the case of basal slip.

\subsection{Strain hardening in the twinned micropillars}

The stress-strain curves of the micropillars oriented for twinning showed a region with strong strain hardening when the applied strain was higher than 5\%. Similar behaviour has been reported during micropillar compression [28,31] as well as uniaxial [54] and plane strain compression [55] Mg and $\mathrm{Mg}$ alloys single crystals oriented for twinning. The origin of this strain hardening has been attributed to the activation of $\langle c+a\rangle$ pyramidal slip to accommodate the deformation in the twinned crystal, which is not suitable oriented for basal slip. Moreover, other authors also pointed out the strengthening may also be caused by the presence of TTB which may block dislocation slip [31]. It should also be noted that the strain hardening rate increased rapidly with the Al content for all micropillar sizes. 
After twinning, the compression direction was close to the $c$-axis and new micropillar compression tests were carried out in specimens of $\mathrm{Mg}-4$ at.\% $\mathrm{Al}$ and $\mathrm{Mg}-9$ at.\%Al alloys oriented in [0001] direction. There are 5 equivalent pyramidal slip systems in this orientation with high Schmid factors (between 0.46 and 0.43 , see Table 1) which are similar to those in the [0116] orientation within the twinned region of the micropillars in Fig. 6 (between 0.37 and 0.49 in Table 1). Three tests were carried out for each alloy in micropillars of $7 \times 7 \mu \mathrm{m}^{2}$ cross-section to ascertain the CRSS for $\langle c+a>$ pyramidal slip as a function of the $\mathrm{Al}$ content. They were not performed in pure $\mathrm{Mg}$ because the CRSS for pyramidal slip is well established from previous studies [30,32]. Two representative resolved shear stress-strain curves obtained from these experiments are plotted in Fig. 10a. The initial response is elastic followed by a plastic region with linear strain hardening. This behaviour is equivalent to that found in pure $\mathrm{Mg}$ deformed in compression along the [0001] direction [30,32]. The analysis of the deformed micropillars in the SEM showed the presence of slip traces parallel to the basal plane (Fig. 11a), very similar to those found

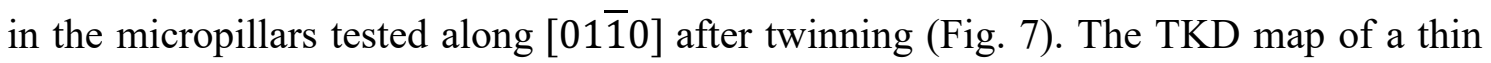
lamella extracted from that deformed pillar of $\mathrm{Mg}-4$ at.\%Al did not show any evidence of twinning (Fig. 11b), indicating that the plastic deformation was accommodated by dislocation slip.
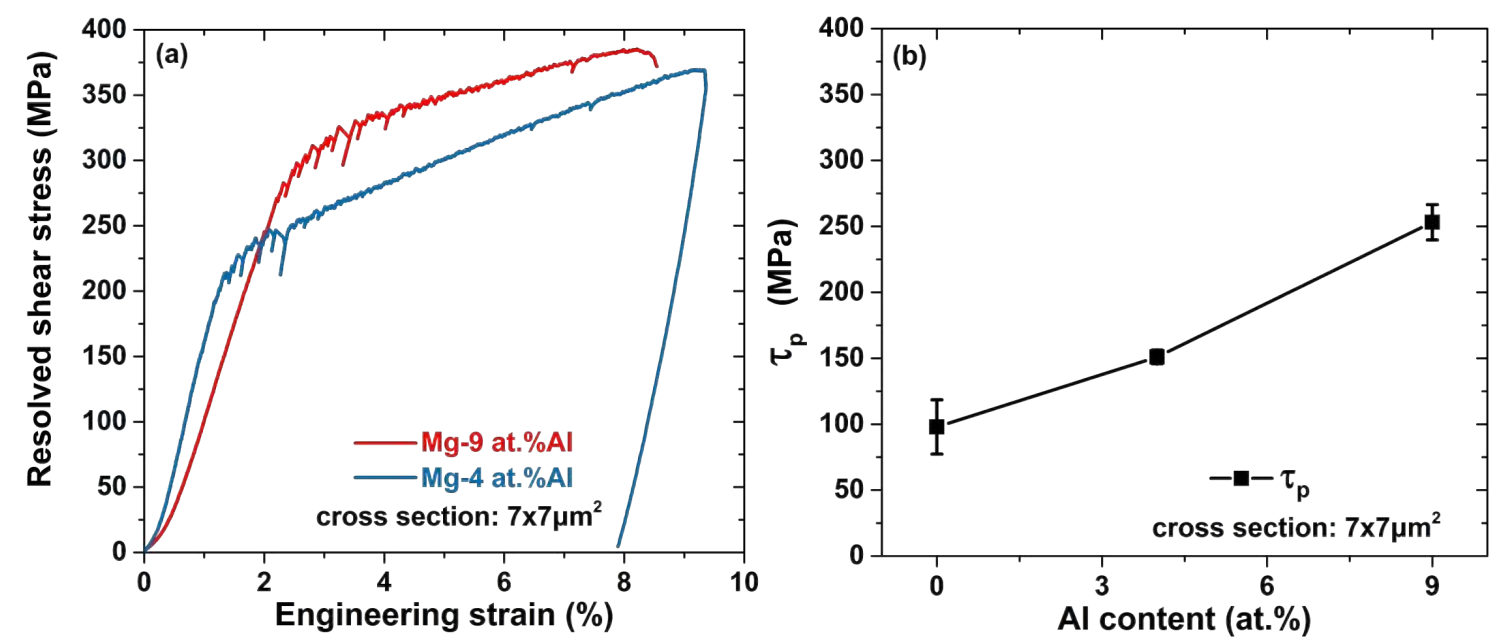

Fig. 10 (a) Representative resolved shear stress - e strain curves of micropillars of $5 \times 5$ and $7 \times 7$ $\mu \mathrm{m}^{2}$ cross-section of Mg-4 at.\%Al, and Mg-9 at.\%Al. (b) CRSS to activate pyramidal dislocation slip in $\mathrm{Mg}, \mathrm{Mg}-4$ at.\%Al and $\mathrm{Mg}-9$ at.\%Al. The results for pure $\mathrm{Mg}$ are obtained from $[30,32]$.

The CRSS for the initiation of plastic slip could be easily computed from the onset of non-linear deformation in Fig. 10a and the average values (as well as the standard 
deviation) are plotted in Fig. $10 \mathrm{~b}$ as a function of the $\mathrm{Al}$ content. The experimental results in the case of pure $\mathrm{Mg}$ included in this figure are taken from $[30,32]$. The dislocation structure in the deformed micropillars was analysed by TEM. As found within the twin region of the micropillars deformed along [01̄0], $<a>$ prismatic dislocations as well as $<c+a>$ pyramidal dislocations were found under the diffraction conditions $g=[0001]$ (Fig. 11c) and $g=[01 \overline{1} 0]$ (Fig. 11d), respectively. Thus, plastic deformation along [0001] was mainly accommodated by the pyramidal slip, and the influence of the $\mathrm{Al}$ content on the CRSS for pyramidal slip can be found in Fig. 10b.

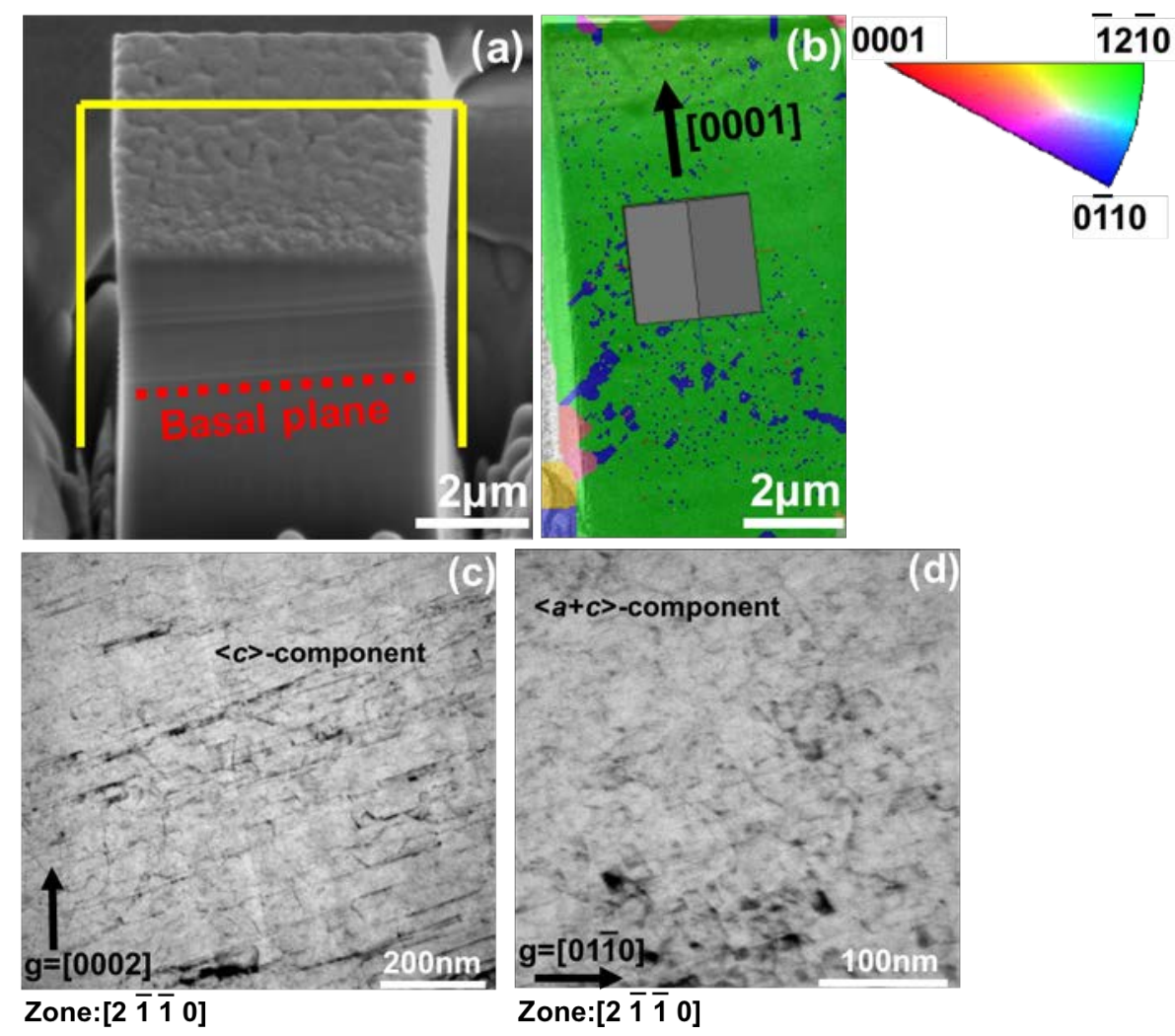

Fig. 11 (a) SEM micrograph of the Mg-4 at.\%Al micropillar deformed along the [0001] direction. (b) $t$-EBSD maps of a thin lamella extracted from the micropillar in (a). (c) TEM micrographs of that lamella under the condition $g=[0002]$ to reveal the $\langle c\rangle$ dislocations. (d) Same as (c) observed under $g=[01 \overline{1} 0]$ to reveal $<a>$ dislocations.

The presence of solute atoms increased dramatically the CRSS for pyramidal slip ( $\tau_{p} \approx 98 \mathrm{MPa}$ in pure $\mathrm{Mg}$ to $\tau_{p} \approx 250 \mathrm{MPa}$ in $\mathrm{Mg}-9$ at.\%Al) and these differences may explain the effect of the Al content of the strain hardening rate of the micropillars deformed along [01ำ] after twinning. In the case of pure $\mathrm{Mg}$, plastic deformation by pyramidal slip is activated when the CRSS on the pyramidal system reaches around 100 $\mathrm{MPa}$, and this stress level is attained at low strains when the applied engineering stress in 
the micropillar reaches $\approx 200 \mathrm{MPa}(\approx 6 \%$ in Fig. $6 \mathrm{a})$. Thus, most of the strain hardening of the twinned $\mathrm{Mg}$ micropillar up to $10 \%$ strain is associated to the interaction between pyramidal dislocations and also the interaction of pyramidal dislocations with TTB [30,32]. Activity of pyramidal dislocations was very large under these conditions, as shown in Figs. 3c and 3d. Nevertheless, the CRSS to activate pyramidal slip in the twinned Mg-9 at.\%Al micropillars was much higher (250 MPa) and compressive stress higher than $500 \mathrm{MPa}$ were necessary to promote pyramidal slip. These stresses were only achieved at very high strains $(>8 \%)$ in the micropillars with $5 \times 5$ and $7 \times 7 \mu m^{2}$ crosssection. Thus, in the absence of pyramidal slip and with very limited basal slip activity, the deformation has to be partially accommodated by elastic strains, leading to very large strain hardening rates in the $\mathrm{Mg}-\mathrm{Al}$ alloys, as compared with pure $\mathrm{Mg}$. This mechanism was confirmed by limited presence of $\langle c+a\rangle$ pyramidal dislocations in the $\mathrm{Mg}-\mathrm{Al}$ micropillars after $10 \%$ strain (Figs. $5 \mathrm{~b}$ and c).

\section{Conclusions}

The effect of $\mathrm{Al}$ content on the critical resolved shear stress for twin nucleation and growth was analysed by the combination of diffusion couples with micropillar compression tests. Micropillars of square cross cross-sections in the range $3 \times 3 \mu \mathrm{m}^{2}$ to $7 \mathrm{x} 7 \mu \mathrm{m}^{2}$ were deformed along [01 $\left.\overline{1} 0\right]$. The deformation mechanisms were independent of the micropillar dimensions and Al content. The stress for twin nucleation was identified by a sudden strain burst due to the nucleation of one or two twin variants in the upper region of the micropillar. Afterwards, twin propagation occurred at a constant stress until the whole micropillar was twinned and deformation was partially accommodated by deformation of the twinned micropillar by pyramidal and basal slip. These mechanisms were accompanied by a strong strain hardening.

Size effects for micropillars of $5 \times 5 \mu \mathrm{m}^{2}$ to $7 \times \mathrm{x}^{2} \mathrm{~m}^{2}$ were negligible and the critical resolved shear stresses for twin nucleation and growth could be obtained from the applied stress and the Schmid factors. The critical resolved shear for twin nucleation was higher than that for twin growth both increased by the same amount with the Al content. Nevertheless, the increase was small ( $\approx 10 \mathrm{MPa}$ ) for 4 at.\%Al and large (up to $60-70 \mathrm{MPa}$ ) for 9 at.\%Al. The solute strengthening in the dilute regime ( $<5$ at.\%Al) was in agreement with the predictions of Labusch-type models based of first principles calculations. However, this approach underestimated the strengthening for large solute contents. In 
addition, it was shown $\mathrm{Al}$ atoms are more effective in increasing the critical resolved shear stresses for twin nucleation and growth than for basal slip.

Compression tests in micropillars oriented along [0001] showed that the strain hardening in the twinned micropillars was linked to pyramidal slip. It was found that the critical shear stress for pyramidal slip increased rapidly with the $\mathrm{Al}$ content from $98 \mathrm{MPa}$ in pure $\mathrm{Mg}$ to $250 \mathrm{MPa}$ in $\mathrm{Mg}-9$ at.\%Al. Thus, the information about the critical resolved shear stress for twinning and pyramidal slip in $\mathrm{Mg}$-Al obtained in this investigation, together with the corresponding results for basal slip in [21] show that the plastic anisotropy of $\mathrm{Mg}$ alloys increases with the $\mathrm{Al}$ content.

\section{Acknowledgements}

This investigation was supported by the European Research Council (ERC) under the European Union's Horizon 2020 research and innovation programme (Advanced Grant VIRMETAL, grant Agreement no. 669141). Ms. J-Y. Wang acknowledges the financial support from the China Scholarship Council, grant no. 201506890002.

\section{References}

[1] B.L. Mordike, T. Ebert, Magnesium Properties - applications - potential, Mater. Sci. Eng. A. 302 (2001) 37-45. doi:10.1016/S0921-5093(00)01351-4.

[2] A.A. Luo, Magnesium: Current and potential automotive applications, Jom. 54 (2002) 42-48. doi:10.1007/BF02701073.

[3] M.K. Kulekci, Magnesium and its alloys applications in automotive industry, Int J Adv Manuf Technol. 39 (2008) 851-865. doi:10.1007/s00170-007-1279-2.

[4] M. Bamberger, G. Dehm, Trends in the Development of New Mg Alloys, Annu. Rev. Mater. Res. 38 (2008) 505-533. doi:10.1146/annurev.matsci.020408.133717.

[5] S.R. Agnew, J.F. Nie, Preface to the viewpoint set on: The current state of magnesium alloy science and technology, Scr. Mater. 63 (2010) 671-673. doi:10.1016/j.scriptamat.2010.06.029.

[6] H. Yoshinaga, R. Horiuchi, Deformation mechanisms in magnesium single crystals compressed in the direction parallel to hexagonal axis, Trans. JIM. 4 (1963) 1-8. doi:10.2320/matertrans1960.4.1.

[7] H. Conrad, W.D. Robertson, Effect of temperature on the flow stress and strain hardening coefficient of magnesium single crystals, Jom. 9 (1957) 503-512.

[8] E.C. Burke, W.R. Hibbard, Plastic Deformation of Magnesium Single Crystals, Jom. 4 (1952) 295-303.

[9] H.T. S. Ando, K. Nakamura, K. Takashima, $\{1122\}\langle 1123\rangle$ Slip in magnesium single crystal, J. Japan Inst. Light Met. 42 (1992) 765-771.

[10] J. Wang, I.J. Beyerlein, C.N. Tomé, An atomic and probabilistic perspective on twin nucleation in Mg, Scr. Mater. 63 (2010) 741-746. doi:10.1016/j.scriptamat.2010.01.047.

[11] J.W. Christian, S. Mahajan, Deformation twinning, Prog. Mater. Sci. 39 (1995) 
1-157. doi:10.1016/0079-6425(94)00007-7.

[12] N. Thompson, D.J. Millard, XXXVIII. Twin formation, in cadmium, Philos. Mag. 43 (1952) 422-440. doi:10.1080/14786440408520175.

[13] S. Mendelson, Dislocation dissociations in hep metals, J. Appl. Phys. 41 (1970) 1893-1910. doi:10.1063/1.1659139.

[14] J. Wang, R.G. Hoagland, J.P. Hirth, L. Capolungo, I.J. Beyerlein, C.N. Tomé, Nucleation of a $\left(1^{-} 012\right)$ twin in hexagonal close-packed crystals, Scr. Mater. 61 (2009) 903-906. doi:10.1016/j.scriptamat.2009.07.028.

[15] J. Wang, J.P. Hirth, C.N. Tomé, (over(1, ) 0 ll 2) Twinning nucleation mechanisms in hexagonal-close-packed crystals, Acta Mater. 57 (2009) 55215530. doi:10.1016/j.actamat.2009.07.047.

[16] J. Wang, S.K. Yadav, J.P. Hirth, C.N. Tomé, I.J. Beyerlein, Pure-Shuffle Nucleation of Deformation Twins in Hexagonal-Close-Packed Metals, Mater. Res. Lett. 1 (2013) 126-132. doi:10.1080/21663831.2013.792019.

[17] J. Jeong, M. Alfreider, R. Konetschnik, D. Kiener, S.H. Oh, In-situ TEM observation of $\left\{101^{-} 2\right\}$ twin-dominated deformation of Mg pillars: Twinning mechanism, size effects and rate dependency, Acta Mater. 158 (2018) 407-421. doi:10.1016/j.actamat.2018.07.027.

[18] A. Serra, D.J. Bacon, R.C. Pond, The crystallography and core structure of twinning dislocations in H.C.P. metals, Acta Metall. 36 (1988) 3183-3203. doi:10.1016/0001-6160(88)90054-5.

[19] A. Akhtar, E. Teghtsoonian, Solid Solution Strengthening of Magnesium Single Crystals - I Alloying Behaviour in Basal Slip, Acta Metall. 17 (1969) 13391349. doi:10.1016/0001-6160(69)90151-5.

[20] A. Akhtar, E. Teghtsoonian, Substitutional solution hardening of magnesium single crystals, Philos. Mag. 25 (1972) 897-916.

[21] J.-Y. Wang, N. Li, R. Alizadeh, M.A. Monclús, Y.W. Cui, J.M. MolinaAldareguía, J. LLorca, Effect of solute content and temperature on the deformation mechanisms and critical resolved shear stress in $\mathrm{Mg}-\mathrm{Al}$ and $\mathrm{Mg}$ Zn alloys, Acta Mater. 170 (2019) 155-165. doi:10.1016/j.actamat.2019.03.027.

[22] J.J. Bhattacharyya, F. Wang, P.D. Wu, W.R. Whittington, H. El Kadiri, S.R. Agnew, Demonstration of alloying, thermal activation, and latent hardening effects on quasi-static and dynamic polycrystal plasticity of Mg alloy, WE43-T5, plate, Int. J. Plast. 81 (2016) 123-151. doi:10.1016/j.ijplas.2016.01.005.

[23] N. Stanford, R.K.W. Marceau, M.R. Barnett, The effect of high yttrium solute concentration on the twinning behaviour of magnesium alloys, Acta Mater. 82 (2015) 447-456. doi:10.1016/j.actamat.2014.09.022.

[24] M. Arul Kumar, I.J. Beyerlein, R.A. Lebensohn, C.N. Tomé, Role of alloying elements on twin growth and twin transmission in magnesium alloys, Mater. Sci. Eng. A. 706 (2017) 295-303. doi:10.1016/j.msea.2017.08.084.

[25] S.R. Agnew, M.H. Yoo, C.N. Tomé, Application of texture simulation to understanding mechanical behavior of $\mathrm{Mg}$ and solid solution alloys containing $\mathrm{Li}$ or Y, Acta Mater. 49 (2001) 4277-4289. doi:10.1016/S1359-6454(01)00297-X.

[26] J. Wang, M. Ramajayam, E. Charrault, N. Stanford, Quantification of precipitate hardening of twin nucleation and growth in $\mathrm{Mg}$ and $\mathrm{Mg}-5 \mathrm{Zn}$ using micro-pillar compression, Acta Mater. 163 (2019) 68-77. doi:10.1016/j.actamat.2018.10.009.

[27] N. Stanford, M.R. Barnett, Solute strengthening of prismatic slip, basal slip and \{10-12\} twinning in Mg and Mg-Zn binary alloys, Int. J. Plast. 47 (2013) 165181. doi:10.1016/j.ijplas.2013.01.012.

[28] G.D. Sim, G. Kim, S. Lavenstein, M.H. Hamza, H. Fan, J.A. El-Awady, 
Anomalous hardening in magnesium driven by a size-dependent transition in deformation modes, Acta Mater. 144 (2018) 11-20.

doi:10.1016/j.actamat.2017.10.033.

[29] Z.H. Aitken, H. Fan, J.A. El-Awady, J.R. Greer, The effect of size, orientation and alloying on the deformation of AZ31 nanopillars, J. Mech. Phys. Solids. 76 (2015) 208-223. doi:10.1016/j.jmps.2014.11.014.

[30] G.S. Kim, Small Volume Investigation of Slip and Twinning in Magnesium Single Crystals, PhD thesis. University of Grenoble, 2011.

[31] K.E. Prasad, K. Rajesh, U. Ramamurty, Micropillar and macropillar compression responses of magnesium single crystals oriented for single slip or extension twinning, Acta Mater. 65 (2014) 316-325. doi:10.1016/j.actamat.2013.10.073.

[32] E. Lilleodden, Microcompression study of $\operatorname{Mg}\left(\begin{array}{llll}0 & 0 & 0 & 1\end{array}\right)$ single crystal, Scr. Mater. 62 (2010) 532-535. doi:10.1016/j.scriptamat.2009.12.048.

[33] C.M. Byer, B. Li, B. Cao, K.T. Ramesh, Microcompression of single-crystal magnesium, Scr. Mater. 62 (2010) 536-539. doi:10.1016/j.scriptamat.2009.12.017.

[34] J. Wang, N. Stanford, Investigation of precipitate hardening of slip and twinning in $\mathrm{Mg} 5 \% \mathrm{Zn}$ by micropillar compression, Acta Mater. 100 (2015) 53-63. doi:10.1016/j.actamat.2015.08.012.

[35] Y. Liu, N. Li, M. Arul Kumar, S. Pathak, J. Wang, R.J. McCabe, N.A. Mara, C.N. Tomé, Experimentally quantifying critical stresses associated with basal slip and twinning in magnesium using micropillars, Acta Mater. 135 (2017) 411-421. doi:10.1016/j.actamat.2017.06.008.

[36] H. Zhang, B.E. Schuster, Q. Wei, K.T. Ramesh, The design of accurate microcompression experiments, Scr. Mater. 54 (2006) 181-186. doi:10.1016/j.scriptamat.2005.06.043.

[37] D. Kiener, C. Motz, G. Dehm, Micro-compression testing: A critical discussion of experimental constraints, Mater. Sci. Eng. A. 505 (2009) 79-87. doi:10.1016/j.msea.2009.01.005.

[38] I.N. Sneddon, The relation between load and penetration in the axisymmetric boussinesq problem for a punch of arbitrary profile, Int. J. Eng. Sci. 3 (1965) 4757. doi:10.1016/0020-7225(65)90019-4.

[39] J.R. Greer, W.C. Oliver, W.D. Nix, Size dependence of mechanical properties of gold at the micron scale in the absence of strain gradients, Acta Mater. 53 (2005) 1821-1830. doi:10.1016/j.actamat.2004.12.031.

[40] D. Kiener, C. Motz, G. Dehm, Micro-compression testing: A critical discussion of experimental constraints, Materials Science and Engineering A, 505 (2009) 79-87. doi: 10.1016/j.msea.2009.01.005.

[41] L.A. Giannuzzi, F.A. Stevie, A review of focused ion beam milling techniques for TEM specimen preparation, Micron. 30 (1999) 197-204. doi:10.1016/S09684328(99)00005-0.

[42] R.E. Reed-Hill, W.D. Robertson, Deformation of magnesium single crystals by non basal slip, Jom. 9 (1957) 496-502.

[43] E.W. Kelly, W.F. Hosford, Plane-strain compression of magnesium and magnesium alloy crystals, Trans. Met. Soc. AIME. 242 (1968) 5-13.

[44] Ping Yang, EBSD application and technique, 2007.

[45] S. Morozumi, M. Kikuchi, H. Yoshinaga, Electron Microscope Observation in and around \{1 1 bar102\} Twins in Magnesium, Trans. Japan Inst. Met. 17 (1976) 158-164. doi:10.2320/matertrans 1960.17.158.

[46] C.M. Byer, K.T. Ramesh, Effects of the initial dislocation density on size effects 
in single-crystal magnesium, Acta Mater. 61 (2013) 3808-3818.

doi:10.1016/j.actamat.2013.03.019.

[47] Q. Yu, Z. Shan, J. Li, X. Huang, L. Xiao, J. Sun, E. Ma, Strong crystal size effect on deformation twinning, Nature. 463 (2010) 335-338. doi:10.1038/nature08692.

[48] J. Wang, M. Ramajayam, E. Charrault, N. Stanford, Quantification of precipitate hardening of twin nucleation and growth in $\mathrm{Mg}$ and $\mathrm{Mg}-5 \mathrm{Zn}$ using micro-pillar compression, Acta Mater. 163 (2019) 68-77. doi:10.1016/j.actamat.2018.10.009.

[49] Q. Yu, L. Qi, K. Chen, R.K. Mishra, J. Li, A.M. Minor, The nanostructured origin of deformation twinning, Nano Lett. 12 (2012) 887-892. doi:10.1021/nl203937t.

[50] Q. Yu, R.K. Mishra, A.M. Minor, The Effect of Size on the Deformation Twinning Behavior in Hexagonal Close-Packed Ti and Mg, 64 (2012) 12351240. doi:10.1007/s11837-012-0437-7.

[51] M. Ghazisaeidi, L.G. Hector, W.A. Curtin, Solute strengthening of twinning dislocations in Mg alloys, Acta Mater. 80 (2014) 278-287.

doi:10.1016/j.actamat.2014.07.045.

[52] G.P.M. Leyson, W.A. Curtin, L.G. Hector, C.F. Woodward, Quantitative prediction of solute strengthening in aluminium alloys, Nat. Mater. 9 (2010) 750755. doi:10.1038/nmat2813.

[53] G.P.M. Leyson, L.G. Hector, W.A. Curtin, First-principles prediction of yield stress for basal slip in Mg-Al alloys, Acta Mater. 60 (2012) 5197-5203. doi:10.1016/j.actamat.2012.06.020.

[54] F. Wang, K. Hazeli, K.D. Molodov, C.D. Barrett, T. Al-Samman, D.A. Molodov, A. Kontsos, K.T. Ramesh, H. El Kadiri, S.R. Agnew, Characteristic dislocation substructure in $101^{-} 2$ twins in hexagonal metals, Scr. Mater. 143 (2018) 81-85. doi:10.1016/j.scriptamat.2017.09.015.

[55] A. Chapuis, J.H. Driver, Temperature dependency of slip and twinning in plane strain compressed magnesium single crystals, Acta Mater. 59 (2011) 1986-1994. doi:10.1016/j.actamat.2010.11.064. 